\title{
XVIBEUOR
}

\section{Reexamination of Reversal Transition Records from the Tatoosh and the Agno Intrusions: Implications for the Reversal Process}

\author{
Mike Fuller ${ }^{1 *}$ and lan Williams ${ }^{2}$ \\ ${ }^{1}$ University of California at Santa Barbara, California, USA \\ ${ }^{2}$ University of Wisconsin at River Falls, Wisconsin, USA
}

\begin{abstract}
Few reversal records have been obtained from intrusions, although the possibility of a near constant sampling rate by thermal remanent magnetization (TRM) makes them potentially valuable for paleosecular variation (PSV) and reversal records. In the reversal record from the Tatoosh intrusion, in Mt. Rainier National Park, the field intensity decreases by one order of magnitude and is near to its minimum before major transitional directional changes are seen. Field behavior before and after the polarity switch differs, with recovery taking longer than the onset. Paleosecular variation (PSV) loops are seen in the transitional directions along section and away from the reversal region. The availability of two successive well defined PSV loops in the reversal record immediately before the polarity switch reveals that the center point of the loops moving northward and their size increasing, consistent with the northward motion of a weakening dipole field source. The rotation of the Virtual Geomagnetic Pole (VGP) paths in the PSV loops changes from counterclockwise in the reversed field before the polarity switch to clockwise after. The principal result from the Agno batholith on Luzon in the Philippines is a threefold division in the observed transition directions, a precursor, the polarity change and a rebound [1]. The first and third phases are of similar duration and are interpreted to correspond to PSV loops. The polarity switch may be longer. Assuming that westward drift of the field was the same at the time of these intrusion records as it is now, the central three phases in the Agno last at least 5400 years in an intensity low of more than 16,000 years, broadly consistent with well established estimates from sedimentary records. The VGP paths of these reversal records fall on opposite sides of the Pacific from their sites, following in part regions of north south flow in the outermost core, but tests of a possible role of such flow in the reversal process were inconclusive, both in the intrusions and in records from rapidly deposited drift sediments with which they are compared. The VGP paths during reversals may be explained simply by the varying strength of non-dipole field sources within the preferred longitudinal bands - a static field source model for the transition fields [2], but a role for outermost core flow in changing the non-dipole field may be important, as may be motion of a deeper source suggested by the Tatoosh record and field models of the Brunhes/Matuyama reversal.
\end{abstract}

\section{Keywords}

Geomagnetic field, Reversals, Paleosecular variation.

\section{Introduction}

Numerous reversal records have been acquired from sediments and lavas, been reviewed by many authors, and used to test models of the reversal process [1-3]. In contrast only a few transition records have been obtained from intrusions [4-8]. Yet, the possibility of a near constant sampling rate of the field by thermal remanent magnetization (TRM) makes intrusions potentially valuable for paleosecular variation and reversal records, despite the inevitable smoothing due to the time taken for the blocking temperature distribution to pass through the sample.

Our first records were obtained from the Tatoosh intrusion $[5,6]$ in Mount Rainier National Park and from the Laurel Hill intrusion near Mount Hood [6]. Later, other records came from the Agno batholith on the island of Luzon in the Philippines [7] and the Surco intrusion in Chile [8]. By far the most detailed record came from the Tatoosh record. In the Laurell Hill [6] and Surco records [8] good results were obtained as the field entered the transition, but the records became noisy and included some clearly unreliable results in the recovery to normal polarity. They are not discussed further here. The Agno record gives a simpler, but less complete record than the Tatoosh. It is consistent with the partitioning of the transition directions at the midpoint of the reversal into three phases - the precursor, the switch and the rebound [1]. The aims of this paper are

*Corresponding author: Mike Fuller, University of California at Santa Barbara, California, USA, E-mail: mfu3961215@aol.com

Received: September 17, 2015: Accepted: November 27, 2015: Published: November 30, 2015

Copyright: $\odot 2015$ Fuller M, et al. This is an open-access article distributed under the terms of the Creative Commons Attribution License, which permits unrestricted use, distribution, and reproduction in any medium, provided the original author and source are credited. 
to draw attention to the merits of intrusion records, to bring together in one place results from several papers on the Tatoosh intrusion and on the Agno batholiths records, and to use new insights from the old data to help understand the reversal process.

The records from these two intrusions were obtained from very different lengths of section: the distance along section over which the principal directional changes defining the reversal were found in the Tatoosh was $100 \mathrm{~m}$, but in the Agno record it was about 700 $\mathrm{m}$. This draws attention to the principal difficulty encountered with reversal records from intrusions compared with those from lavas: lavas give instantaneous records of the geomagnetic field because they cool in times short compared with field changes, but intrusion records acquire magnetization over times long compared with field changes and will always involve smoothing. Sedimentary records suffer from a similar problem, although the smoothing consequences of the depositional process of magnetization may be simpler and in some cases smoothing can be minimal. This smoothing of the paleomagnetic records from intrusions and sedimentary sections has disadvantages and advantages: short term changes will be lost, or attenuated, but in some cases, longer term trends may be made more evident.

\section{Reversal Record from the Tatoosh Intrusion}

The Tatoosh record yields insights to the reversal process, some of which were noted in the original papers, but others were not sufficiently emphasized and some not even recognized at the time of the earlier work. A K/Ar determination from near to our collection site gave an age of $14.1 \pm 1.1 \mathrm{Myr}$ [5]. Figure 1a illustrates the location of the Tatoosh intrusion on the southern slopes of Mt Rainier. The boundary between the reversed and normally magnetized regions is shown as a dotted line, which can be traced across the outcrop. Figure $1 \mathrm{~b}$ shows the multiple sections from Nisqually Valley, which demonstrated that the cooling front strikes $290^{\circ}$ and dips $30^{\circ}$ southwards, so that to order of magnitude distance along section and vertically downward represent similar times.

As discussed in detail by $\mathrm{Wu}$ et al. [9], the natural remanent magnetization (NRM) associated with individual oriented grains of the major rock-forming minerals of the Tatoosh granodiorite was determined and established the carriers of stable and unstable components of NRM. In addition, rock magnetic parameters were used to characterize the various carriers. Type A NRM is carried by fine particles of magnetite, which occur primarily as inclusions in plagioclase. Electron microscopy revealed a range of particle sizes with some having dimensions of less than a micron. The Type A NRM is magnetically hard, has a narrow range of high blocking temperatures and is carried by fine single domain (SD) and pseudosingle domain (PSD) magnetite. Type B NRM is carried by larger grains of magnetite associated mostly with biotite and partly with hornblende. It is magnetically soft and contains thermally unstable components. AF and thermal demagnetization were used to separate the Type A NRM signal from the Type B NRM.

Since both hornblende and biotite were present during the last stages of crystallization of the Tatoosh, a wet shallow granodioritic magma system is indicated [9]. The solidus temperature of such a system varies from around $700^{\circ} \mathrm{C}$ to $770^{\circ} \mathrm{C}$, so providing more magnetite was not produced subsequently the NRM should be a thermal remanent magnetization (TRM), as appears to be the case from both $\mathrm{AF}$ and thermal demagnetization analysis.

A vertical core away from the reversal region appeared to show PSV (Figure 2). Two nearly complete small loops, each covering about $\sim 2 \mathrm{~m}$ and displaced from each other by a few degrees were found in a total core depth range of $\sim 5 \mathrm{~m}$. The scale of variation is smaller than we see in present secular variation loops, due to the smoothing involved in the acquisition of the NRM. With such a short record it is not clear whether this PSV represents times commensurate with the loops, such as we see over a few hundred years in historical records of secular variation, or over times like the $\sim 1800$ years of a complete cycle of the westward drift of the present field.

The first reversal profile that we obtained was from the east side of Nisqually valley, ES1 in figure 1b. The declination, inclination and intensity results are shown in figure 3a. It is only a partial record showing neither the full field intensity before the onset of the reversal, or the complete recovery. Although the magnitude of NRM after alternating field (AF) demagnetization is plotted as the measure of field intensity throughout the reversal record, standard paleointensity determinations were made and the trends of intensity were consistent with the trends of the AF demagnetized NRM.

The VGP's are shown in figure $3 b$ [5]. The record is of very high quality in parts, e.g., the enhanced PSV loops in plot 3b.4. In other parts, it is not clear how many of the jagged features in the path should be trusted. An obvious one point anomaly is seen the VGP path in plot $3 \mathrm{~b} 5$ and there appear to be others in plots $3 \mathrm{~b} 3$ and 6 .

(a)

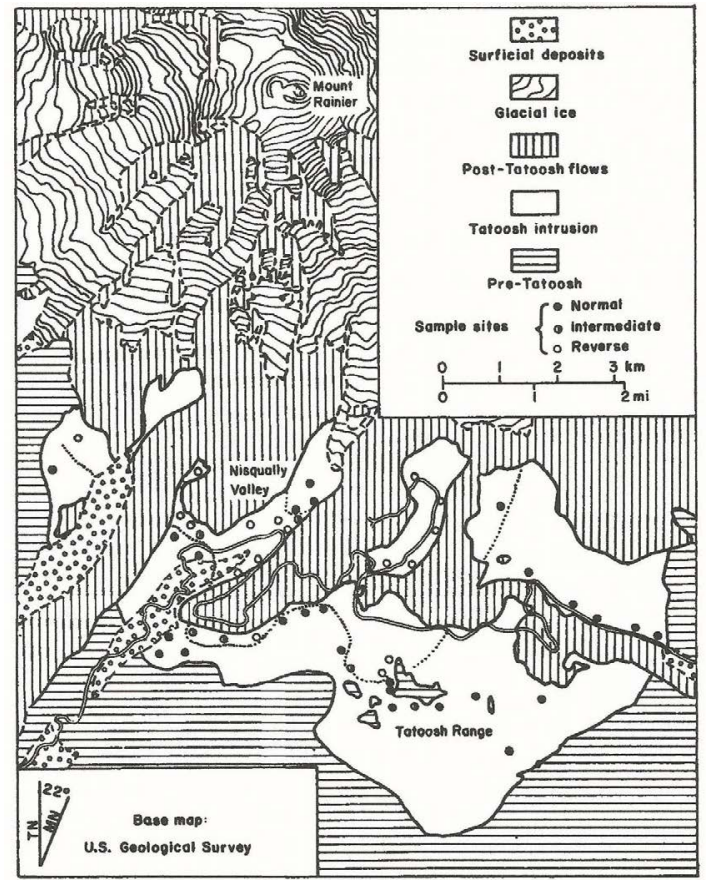

(b)
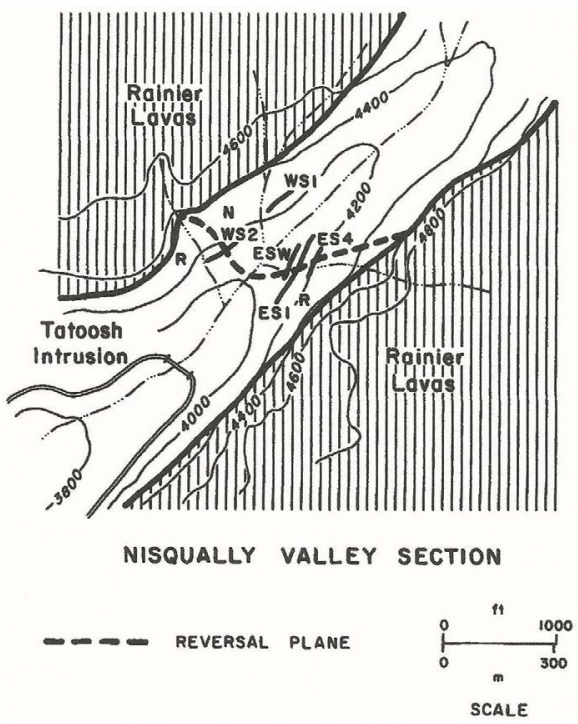

Figure 1: Tatoosh intrusion (a) Southern slope of Mt. Rainier with Tatoosh intrusion showing the reversal boundaries and (b) Nisqually valley with reversal sections sampled and showing the configuration of the cooling front at the midpoint of the reversal. 


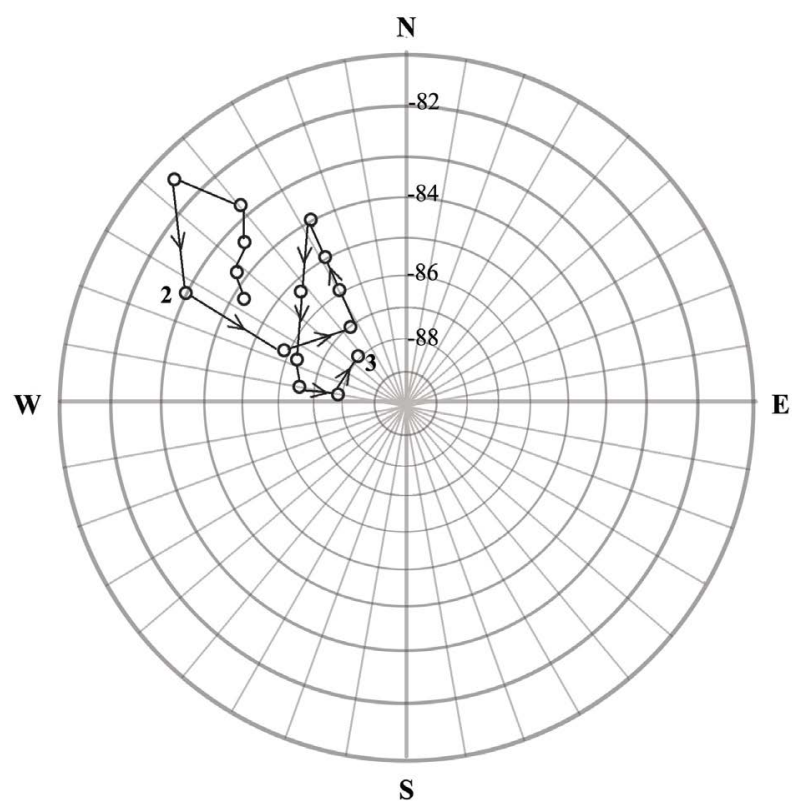

Figure 2: Paleosecular variation (PSV) loops from a vertical core in the Tatoosh intrusion in the reversed region away from the transition.

Figure $3 \mathrm{~b}$ plots 1 and 2 show subdued PSV, when the field intensity is relatively high. The dispersion of the poles is similar to that seen away from the reversal in figure 2, although the same pattern is not evident because figure $3 \mathrm{~b}$ plots 1 and 2 are sampled coarsely over more than $100 \mathrm{~m}$, whereas in figure 2 the sampling is continuous over the core length of less than $5 \mathrm{~m}$. Figure $3 \mathrm{~b} 4$ shows enhanced PSV loops with counter clockwise (CCW) rotation immediately prior to the reversal when the intensity has fallen to a near minimum (figure $3 a)$. These loops are over much longer lengths of section and hence times than those of figure 2. We interpret them as expression of cycles of the westward drift of the field. The second of the two PSV loops has larger amplitude than the first, which is consistent with a decrease in intensity of the dipole field source prior to the reversal switch. The northward movement of the center of these enhanced PSV loops is also consistent with northward movement of the weakening dipole field source that is maintaining the longitudinal control of the VGP path. As we know by analogy with the smoothing of the PSV loops observed away from the reversal, this section must be recording far larger transitional PSV loops, possibly having dimensions ten times greater than observed here and being more complicated, so that smoothing here may make interpretation easier.

The sampling of the section illustrated from the East side of Nisqually Valley does not cover the actual polarity switch well, so a partial record from the West side is given in figure $3 c$, which covers the switch in the western Pacific and the beginning of the rebound over the Americas. This is equivalent to at least part of figure $3 \mathrm{~b} 5$ and both may show the beginning of a rebound. It is evident from the profile in figure $3 \mathrm{a}$ and the plot figure $3 \mathrm{~b} 5$ that high latitude normal poles are seen within meters of the onset of the reversal switch. Unfortunately, the record in figure $3 \mathrm{~b} 5$ includes at least an obvious one point anomaly, so that it is not clear how much of the VGP track immediately following the polarity switch is a rebound and how much noise. The final plot (Figure 3b6) begins with a CW loop accompanied by an intensity increase (Figure 3a).

The continuation of the record after the polarity switch was seen well in a section from the west side of the valley, approximately $300 \mathrm{~m}$ in length (Figure 4). The section comes from beyond the immediate recovery to normal polarity, and so cannot be correlated in detail with the other sections. Initially, it shows a clockwise (CW) loop accompanied by a minor intensity increase. This is then followed by a major intensity peak, which is interrupted by a short low over (a)
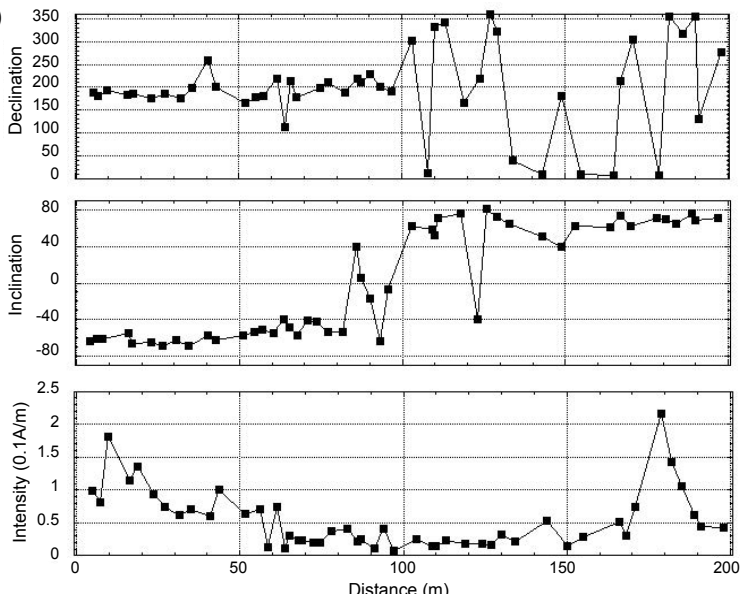

(b)

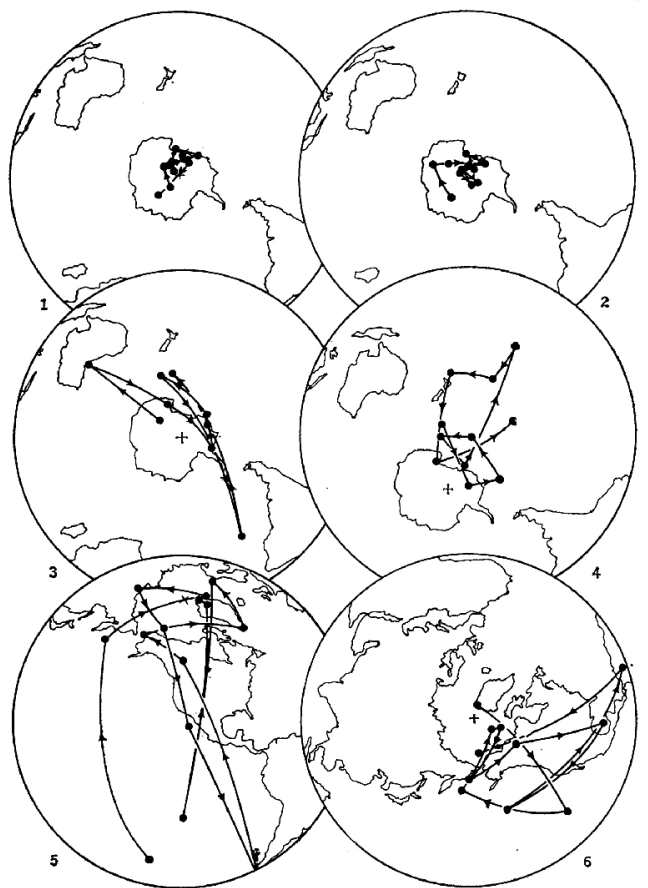

(c)

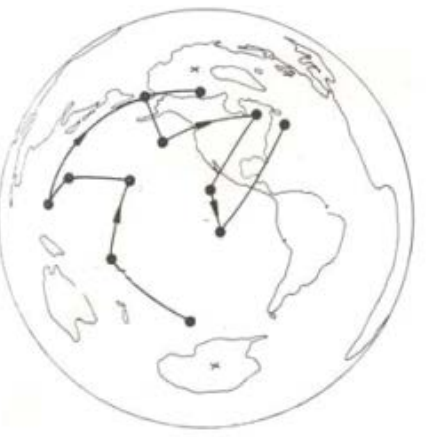

Figure 3: Reversal record from section ES1 on East Side of Nisqually Valley: (a) Declination (D), Inclination (I) and Intensity (Int) along section, (b) VGP path Plots for distances along section: Plots (1) and (2) prior tosectionshown in fig. 3a to show variation before the reversal, Plot (3) 30-60m along section, Plot (4) 60-100m, Plot (5) 100-170m and Plot (6) 170-200m and (c) Polarity switch from section from West side of Nisqually valley.

about $15 \mathrm{~m}$ along section. After this feature, the intensities fall to values comparable to mid transition values and do not recover to non reversing field values. The VGPs are distributed in small concentrated clusters separated by major arc lengths, which is quite different from the PSV seen before the polarity switch. The PSV is however similar to the pattern described by Negrini et al. [10] subsequent to excursions recorded in sedimentary sections. 
(a)
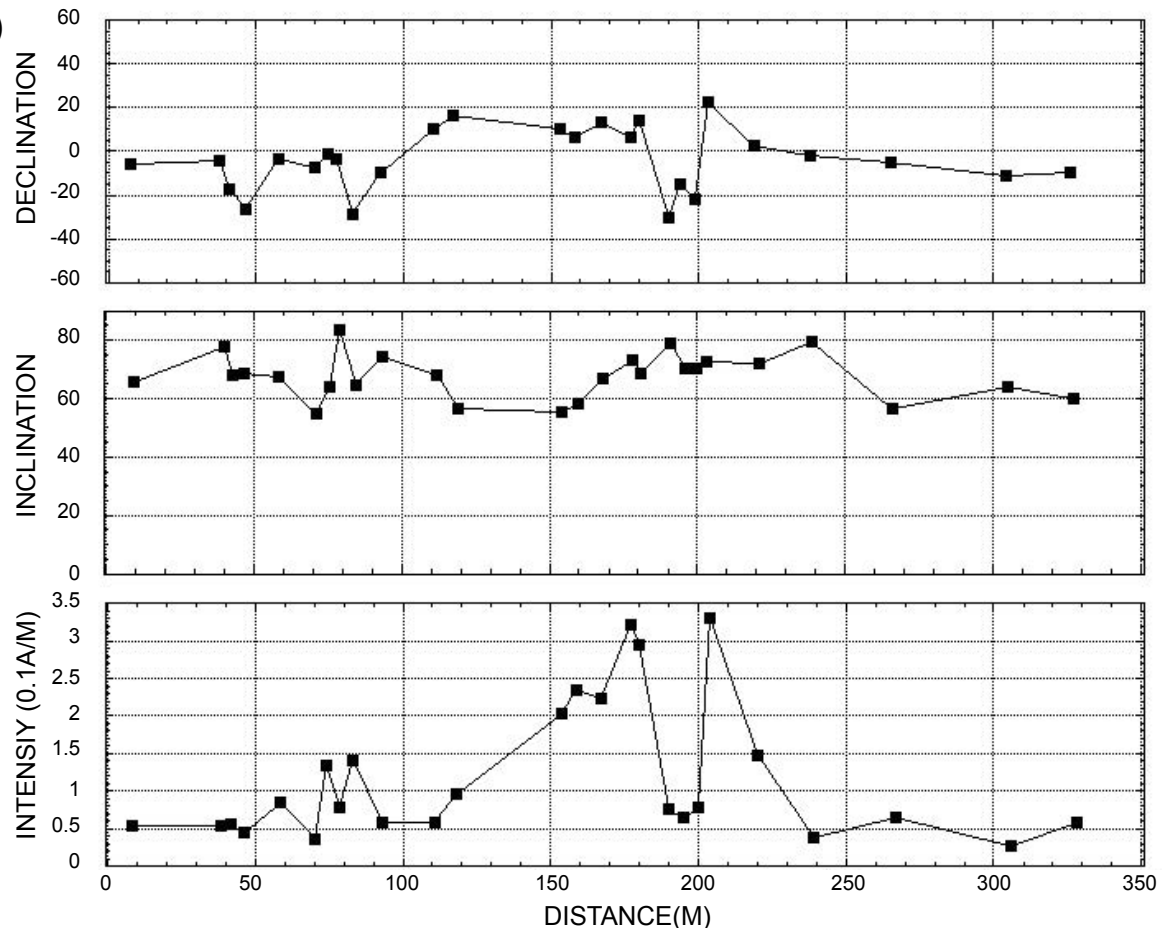

(b)
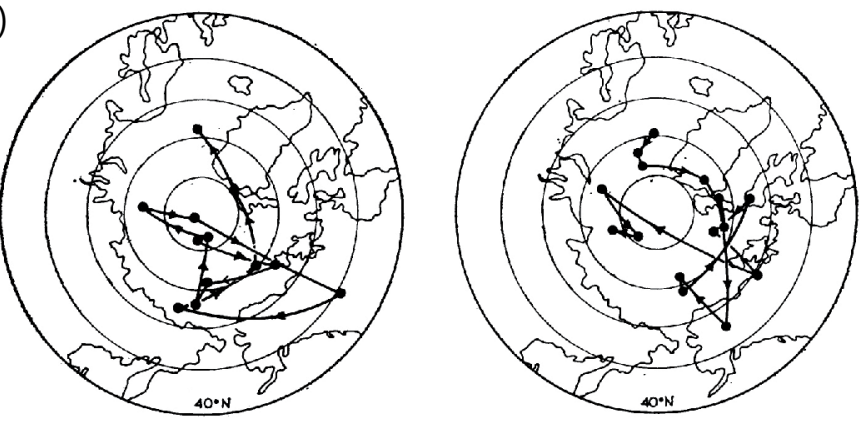

Figure 4: Section from West Side of Nisqually Valley covering time following the main transition. (a) Intensity, Declination and Inclination and (b) VGP paths for $0-120 \mathrm{~m}$ and $150-350 \mathrm{~m}$.

The Tatoosh record differs at equivalent distances before and after the polarity switch. As we move away from the transition a distance of approximately $60 \mathrm{~m}$ before the switch, PSV is subdued and we see from several sections that intensity is systematically climbing to the non-reversing field values. In contrast, even at a much greater distance after the switch the intensity has not recovered nonreversing field strength. Thus the recovery from the reversal takes longer than the onset.

The key observations from the Tatoosh intrusion discussed here are from a number of sections from Nisqually Valley. The most detailed information described above comes from the first sections sampled [5], while the broader patterns come from smoothing of data obtained later from noisier sections [6]. The observations are then as follows. (1) The field intensity decreases during the reversal by one order of magnitude and is near to reaching its minimum before major transitional directional changes are seen. (2) The VGP path during the polarity switch tracks across the Western Pacific. (3) Field behavior at equivalent distances along section before and after the reversal differs significantly, so that the reversal process is asymmetrical, with the recovery taking longer than the onset. (4) PSV loops are seen in transitional directions and in a vertical core away from the reversal region. (5) The rotation of the VGPs in the PSV loops switches from CCW before the polarity switch to CW after, (6) the availability of successive PSV loops in the reversal record immediately prior to the reversal reveals that the center points of the loops progresses northward and their size increases as the transition is approached, consistent with the northward motion of a weakening dipole field source during this period. (7) In recovery PSV was found unlike that seen prior to the reversal, but similar to records from sediments after excursions [10].

\section{The Agno Batholith Reversal Record}

The Agno batholith intrudes the Early to Mid-Miocene Zig-Zag formation in the Central Cordillera of Luzon in the Philippines. In places the Zig-zag lies unconformably upon the Agno and so the age of the intrusion must lie within the age range of this formation. A sample taken from near to our sampling sites was dated at $14.8 \pm 0.8$ $\mathrm{Ma}$ [11]. This intrusion and the Tatoosh may therefore have recorded the same reversal.

The Agno record was obtained along two river sections (Figure 5). The reversed samples and the bulk of the intermediate samples were seen in both, but the reversal transitional directions were completed and the intensity approached recovery downstream below the join of the rivers. We attempted to continue the section westward towards the contact with the Zig-Zag formation, but were unable to get satisfactory results.

The rock magnetism of the Agno batholith samples is discussed 


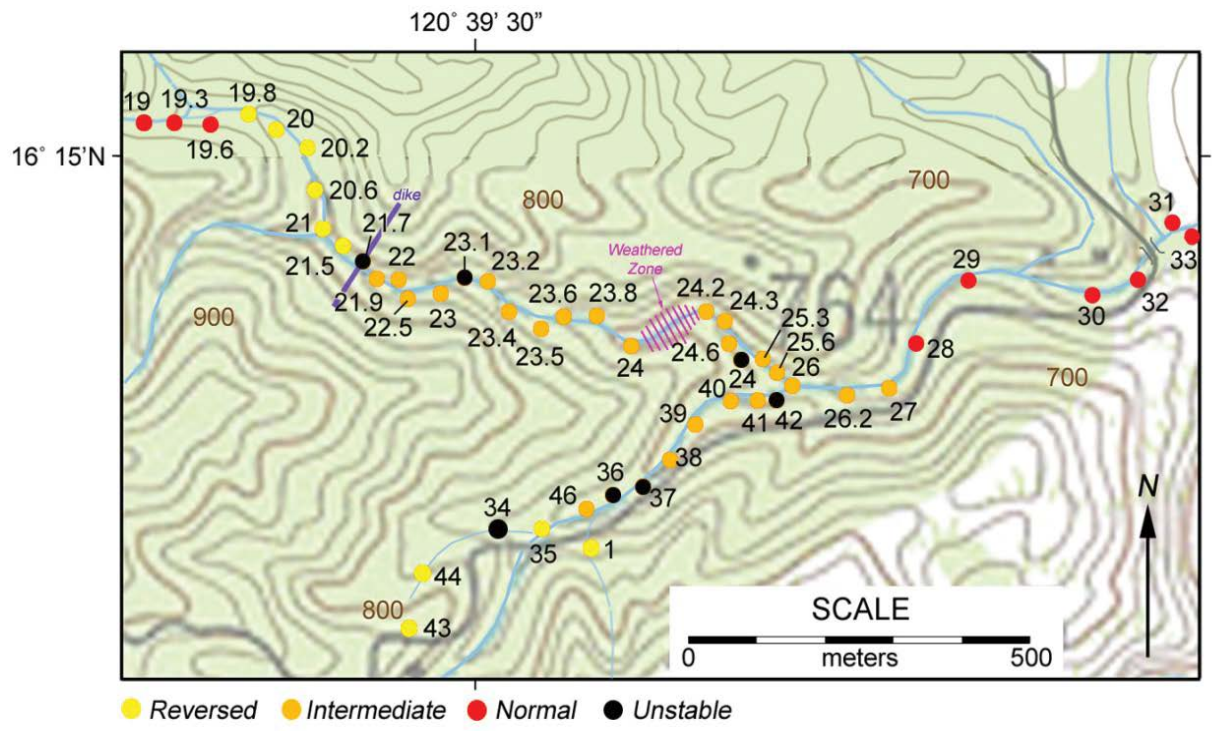

Figure 5: Map of reversal record sites in the Agno batholith.

in detail in the initial paper [7] and it is evident that as in the Tatoosh both soft B type NRM and harder A type are present. There is more B type NRM in the Agno than in the Tatoosh, but both AF and thermal demagnetization were again able to isolate the Type A NRM. Curie points of between 540 and $570^{\circ} \mathrm{C}$ were determined suggesting magnetite, or low Ti titanomagnetite. Comparison of AF demagnetization of NRM and saturation isothermal remanent magnetization (IRMs) indicated that the Type A NRM was carried by PSD or SD material. In addition to using NRM after AF demagnetized to $10 \mathrm{mT}$ or thermally demagnetized to $500^{\circ} \mathrm{C}$ as a measure of the field intensity records, IRMs (saturation Isothermal Remanent Magnetization) and ARM (Anhysteretic Remanent Magnetization) normalization were carried out and shown to give similar results to the AF demagnetized values.

Fisher statistics were computed for individual sites and groups of sites, to generate as near as possible a record with common intervals along the stream sections. 10 of these means covered the actual transition record. Figure 6 gives the results as directions of magnetization before and after tectonic correction for the rotation of this part of the Philippines [12]. The fact that the directions away from the reversal before tectonic correction differ from the present field indicates stability of the NRM at least since the tectonic rotation. The corrected directions show a relatively simple transition path consisting of two complete loops separated by one half loop giving the polarity switch. The first loop is defined by a reversed result and means $1,2,3$, and 4 . The main change in polarity takes place between means 4 and 7 by a single half loop carrying them from a southerly reversed direction to a northerly normal direction. The transition is completed with a small closed loop consisting of transitional means $7,8,9,10$ and the normal direction. There is a clear threefold division in the record of directions.

The mean declination, inclination, and intensity for the groups along the entire section are shown in figure 7 . The declination and inclination progress systematically through the transitional sites from the left, through the first loop (1-4), the polarity switch (4-7) and the second loop with normal values on the right (7-10). Allowing for the arbitrary locations along section of the plotted means, the precursor and rebound appear to be similar in duration, but the polarity switch may be longer. The intensity record does not show the total initial decrease, or the complete recovery after the reversal. The main polarity change is at the intensity minimum and intensity recovery gets underway during the rebound. (a)

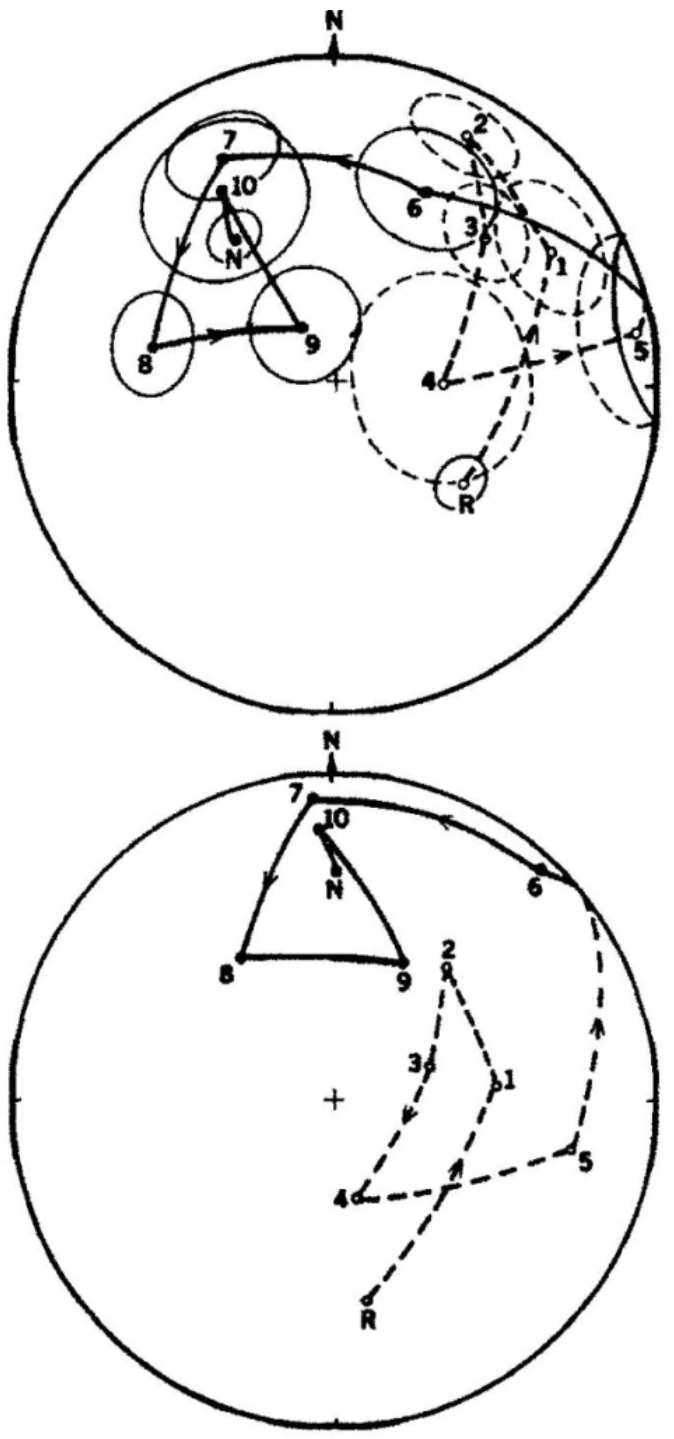

Figure 6: Agno Batholith Directions of AF demagnetized NRM during reversal. (a) In field coordinates as collected with alpha 95's, and (b) the Fisher mean directions in corrected coordinates to take account of tectonic rotations after intrusion. 

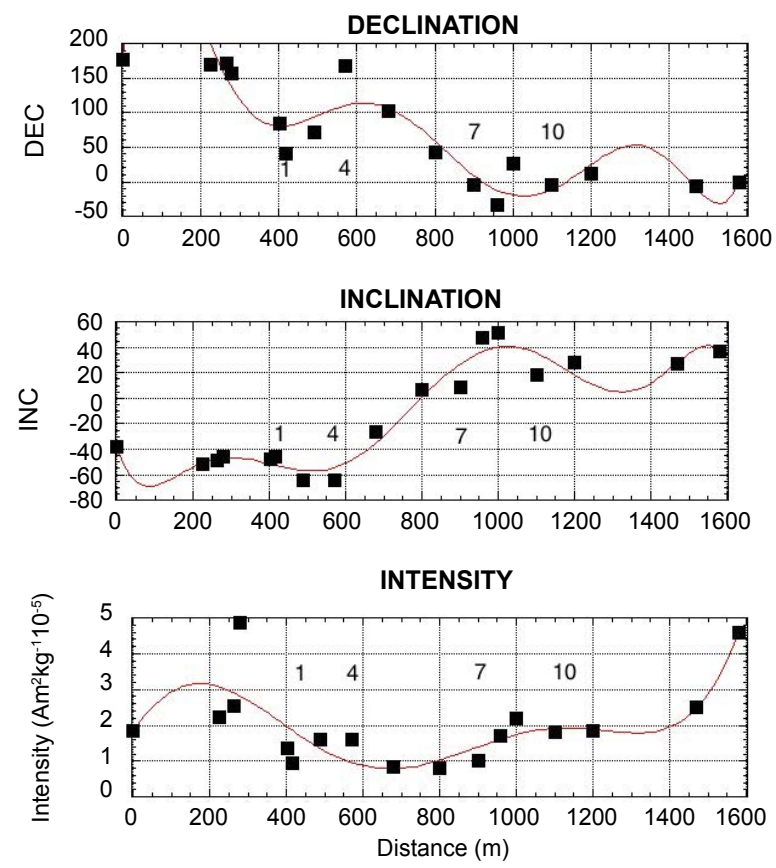

Figure 7: Agno Batholith transition profile: Declination, Inclination and Intensity plotted for individual sites and groups of sites along section with time running from left to right. Sites 1-4 represent the first of the features in the directional record, sites 4-7 the polarity switch and sites 7-10 the third. The solid lines represent low order polynomials fitted to the data.

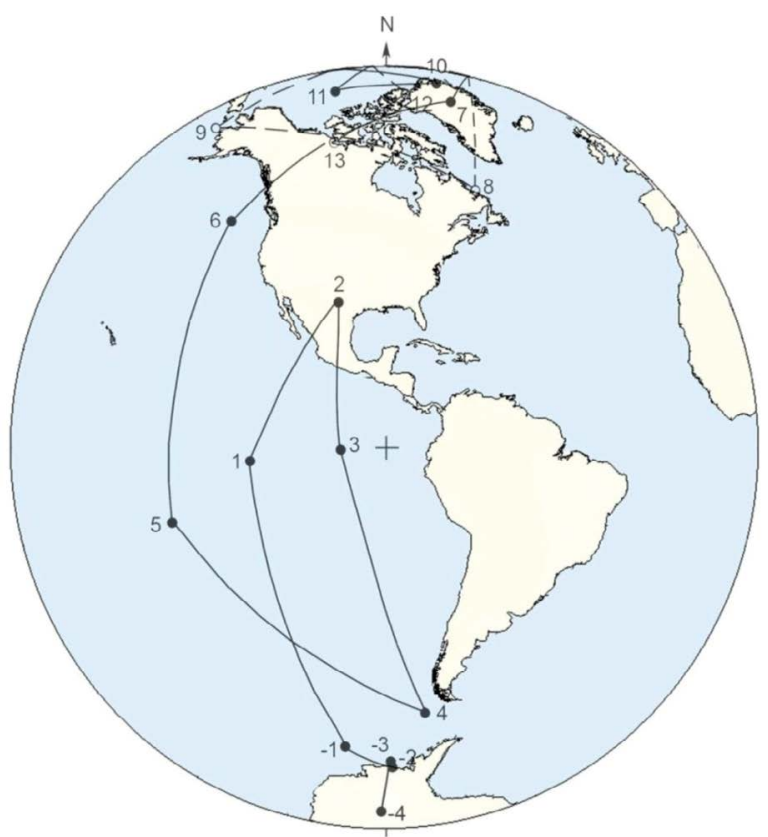

Figure 8: Path of VGP during $\mathrm{R}$ - $\mathrm{N}$ reversal recorded by Agno Batholith. (Solid circles Amercan hemisphere, open opposite hemisphere) Poles - 4 to -1 reversed before transition, 1 to 10 transition poles.

In the VGP presentation, the threefold division is again evident (Figure 8). Negative site numbers give pre-transition poles. The VGP's initial track is over the eastern South Pacific reaching southern North America. The main reversal of polarity takes place as the path moves back over the eastern Pacific and via northern Canada to high northern latitudes. Finally, a smaller loop completes the transition with poles 7, 8, 9 , and 10, leading to post-transitional poles 11 to 13 . The precursor has CW rotation in the VGP paths, but the rebound sense is less clear.
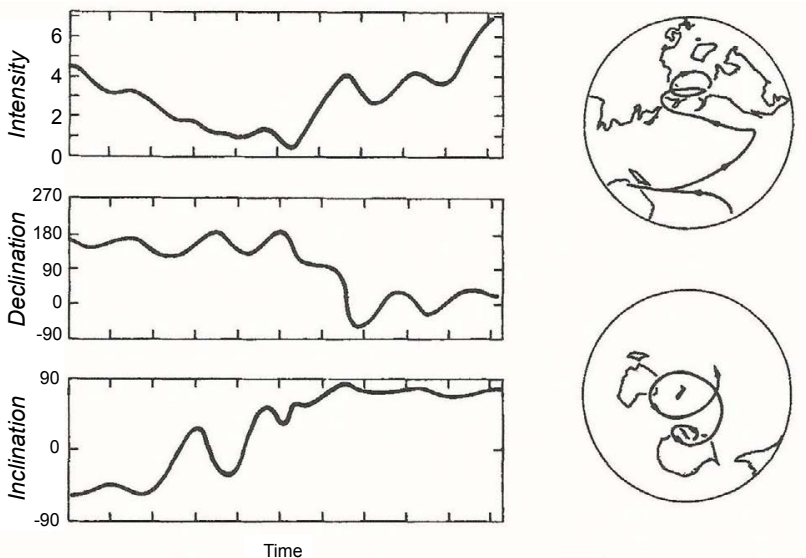

Figure 9: Simulation of reversals by allowing the non-dipole field to drift past the site, as in the present westward drift of the field, while the axial dipole is decreased, reversed and regains its pre-reversal intensity, with an equatorial dipole maintained to constrain the longitude of the VGP path.

The principal results from the Agno are then that there is a threefold division in the observed transition directions consistent with the suggestion of Valet et al. [1]. Using their terminology - (14 ) is the precursor, or phase 1, the change in polarity (4-7) is phase 2 , followed by (7-10), the rebound or phase 3 . The most convincing evidence of this comes from the VGP record (Figure 9), although in the declination and inclination records there is again evidence of features between 1-4 and 7-10 separated by the switch in polarity between 4 and 7. In the Agno record it appears that precursor and the rebound are PSV loops of similar duration, but the polarity switch may be longer, whereas Valet et al. [1] suggested that the polarity switch is much shorter than the other two phases.

\section{Simulation of the Reversal Records from the Tatoosh and Agno Intrusions}

A simulation of these reversal records was carried out earlier [6] and draws attention to important aspects of the reversal process, so it is shown here again (Figure 9). The simulation was made by allowing the non-dipole field to sweep past the site, while the axial dipole was decreased in intensity, reversed and returned to its pre-reversal strength with an equatorial dipole maintained to give a path confined in longitude. Figure 9 illustrates the results of a simulation of the reversal with an arbitrarily chosen number of cycles of the imposed westward drift. The size of the loops increases as the reversal is approached and the axial dipole intensity decreases. After the reversal the size of the loops decreases again. The sense of rotation in the VGP loops is initially counter clockwise, when the field is reversed, but changes to clockwise after the reversal is completed to give a normal field. This latter sense of rotation is consistent with Runcorn's law of clockwise motion in such secular variation loops [13] and the commonly observed sense of rotation in the present field, although the case for localized counter clockwise rotation in a normal field has been developed by Dodson [14] and the situation is more complicated than envisioned in some of the earlier work. The change in rotation sense is readily seen to be the natural consequence of adding the same sequence of small non-dipole vectors to an axial dipole, whose direction reverses. The same switch in rotation of the VGP paths is seen accompanying the polarity change in the Tatoosh record (Figure 3 b), but is not clear in the Agno VGP path (Figure 8). Difficulties with applying this simulation to the interpretation of actual reversal records are that (1) in reality only a part of the non-dipole field drifts westward and (2) the maintenance of a constant equatorial dipole is an arbitrary assumption. Nevertheless the simulation focuses attention on possibly important aspects of the reversals, namely the enhancement of PSV loops during reversals, whose VGP rotation sense changes with the polarity switch. 


\section{Paleosecular Variation (PSV) Loops: The Duration of Reversals and of Events within the Transition}

In both intrusion records and in the simulation, we see PSV loops. In the Tatoosh record, the two PSV loops in figure $2 \mathrm{~b} 4$ take $~ 30$ $\mathrm{m}$ along section to complete, which is equivalent to $\sim 3600$ years given a constant westward drift of the non-dipole field over the past few million years. Elsewhere in the section the evidence for PSV is not so clear, but we estimate $\sim 5400$ years for three westward drift cycles for the principal change in direction and a less precise estimate of $\sim 20,000$ years for the intensity low. In the Agno however the reversal record is simpler and it appears that the precursor and the rebound phases are each single PSV loops, while the polarity switch is of similar duration, but may be longer, so that we get an estimate of $\sim 5400$ years for the principal transition directions in an intensity low of more than 16,000 years. The rate of penetration of the cooling front into the intrusions may however change with time and introduce errors in the estimates of the duration of events within the reversal and indeed of the whole transition in intrusions. Yet these estimated durations of the principal changes in direction and the intensity low in these intrusions are similar to those from studies of the last reversal in sediments from the nearby Sulu and Celebes Seas [15] and in sedimentary records of reversals in general, so that the long term stability in the rate of westward drift is consistent with these observations.

\section{VGP Paths during Reversal Records from Intrusions}

The VGP paths for the Tatoosh and Agno intrusion records are very different. The Agno record is much simpler with a single major CW precursor in the East Pacific, followed by a polarity switch in the Pacific staying east of Hawaii and a minor rebound at high northern latitudes (Figure 8). In contrast, the Tatoosh record has a pair of CCW loops in the South Pacific close to $180^{\circ}$ longitude prior to the polarity switch in the far western Pacific and a possible rebound over N. America (Figure 3). The two records are so different that they may not be for the same reversal despite the similarity of their K/ Ar ages. Alternatively, the difference may be largely due to the site dependence of these VGP paths. Another intrusion reversal record from N. America has a very similar polarity switch to the Tatoosh, being again located in the far western Pacific [4]. From these three intrusion records we find VGP paths during the polarity switch which are on the opposite side of the Pacific to the sites from which they were obtained.

The reversal records from these three intrusions are consistent with the controversial suggestion made first by Clement and Kent [16] and later by Laj et al. [17] that the VGP paths during reversals preferentially follow the longitudes of the Americas and Eastern Pacific and East Asia and the Western Pacific. The occurrence within these same longitude bands of the strongest non-dipole field features, longitudinal flow at the top of the core, circum-Pacific subduction and anomalous mantle P-wave velocity show that these longitudes have special geophysical significance. They are also consistent with thermal energy driving the dynamo to give the non-dipole field.

The interpretation of PSV loops in the VGP paths follows from the role of westward drift, as we saw in the discussion of the simulation of reversals. When added to the deeper source in a "two tiered" dynamo model [2], this then gives the rotations seen in the PSV loops in the intrusion records. The deeper sources are also generally thought to be controlled by thermal driving forces, but there is some evidence of a possible role of precession [18]. The interactions between the observed outermost flow and the proposed flow in the deeper part of the outer core are unclear, as is the interaction of the deeper flow with the inner core.

\section{Field Models of Reversal Transition Fields}

There are few models of the transition fields during reversals [1921] and all are based on sedimentary records. It is therefore of interest (a)
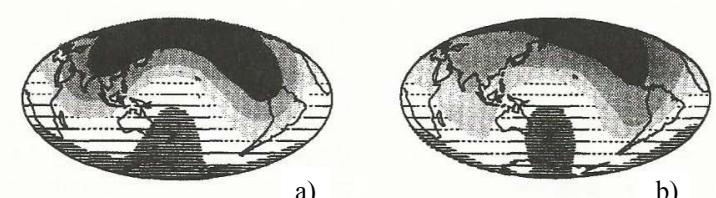

b)
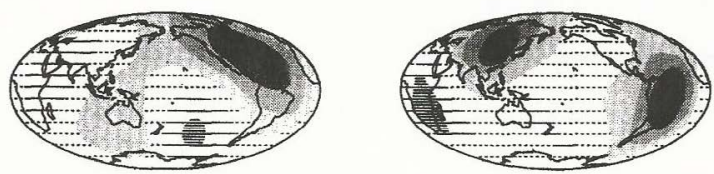

c)

d)
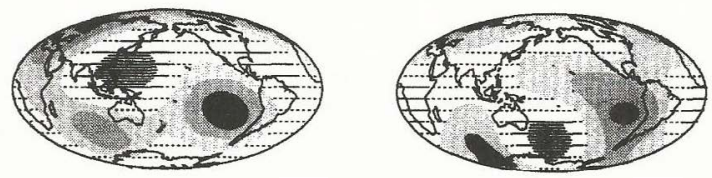

e)

f)
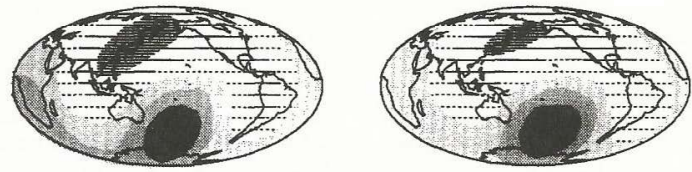

g)

h)

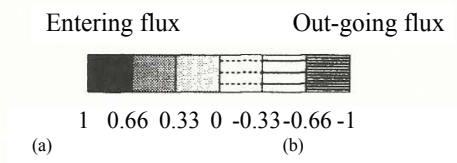

(b)

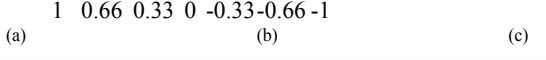
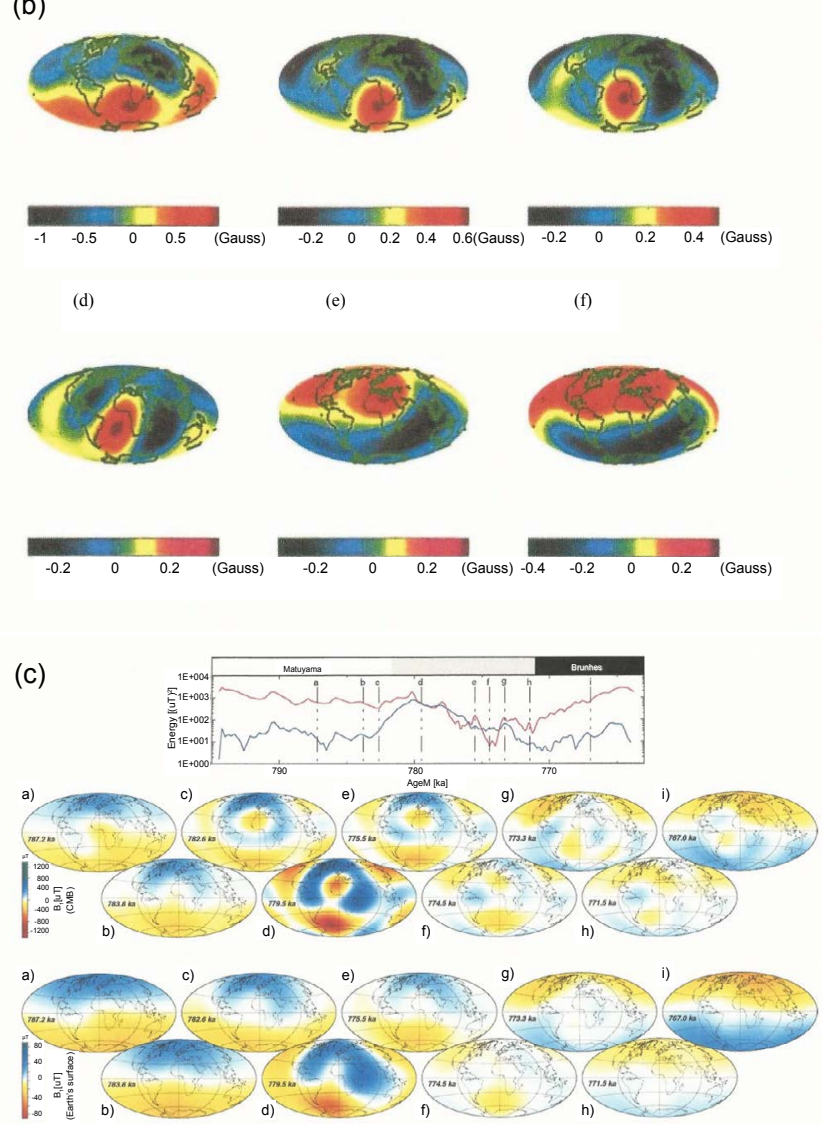

Figure 10: Models of the radial field during reversals. (a) Mazaud [16] the Upper Olduvai N-R reversal; (b) Shao et al., [17] Brunhes-Matuyama R-N reversal. Red colors inward field and blue outward. The time indices of 20 , $30,40,50,60$, and 70 cover the main reversal sequence; (c) Leonhardt and Fabian,[18] Brunhes-Matuyama R-N reversal. Top - intensity of dipole (red) and non-dipole (black) energy throughout reversal, below core mantle boundary and earth surface fields at times indicated in top panel with orange colors inward and blue outward directed fields. 
to see whether these models show evidence of behavior similar to that found in the intrusion records.

The model of Mazaud [19] is for the Upper Olduvai N-R reversal and based on 5 sedimentary sections, which were well dispersed across the planet and had VGP paths that fell over the Americas and East Asia. The records were synchronized using their major features and the directional only data inverted with the constraint that the total field energy outside of the core was invariant. The core mantle radial field derived prior to the reversal showed inward radial field features over North America and East Asia and a single south polar outward directed flux feature (Figure 10a, plots a and b). The southward movement of the inward radial field flux along the longitude of the Americas is the dominant motion bringing about the reversal (Figure $10 \mathrm{a}$ plots $\mathrm{c}$ and $\mathrm{d}$ ). The combination of this with less systematic changes of outward flux features beneath East Asia gives complicated non-axisymmetric transitional fields. These outward features develop in the latest stages of the transition in East Asia and are evident in the post transitional reversed field. This model for an N-R reversal thus has motion of flux along the longitudes of the Americas in common with the R-N Agno record.

In the two field models of the Bruhnes-Matuyama reversal, northward motion of magnetic field flux from the geographic southpole is produced as in the intrusion records. The motion is seen particularly clearly in the field model of Shao et al. [20] for the normalized radial field (Figure 10b). This method makes use of Maxwell's multiple pole theory to recover spherical harmonics, using the relationships of the distribution of VGP's and equatorial virtual poles (EVP's) to the Maxwell poles. Initially the transition model is dominated by a major flux feature in the South Atlantic of the same sign as the inward polar flux of the reversed field at the south geographic pole (Figure 10b). It is flanked by more diffuse flux concentrations of the opposite sign. The dominant flux feature is locked in longitudinal mantle coordinates and moves northward. With the transfer of this major flux feature from the southern to northern hemisphere and the movement of the flanking features of the opposite sign southward the reversal is achieved in this model (Figure 10b, plots $\mathrm{d}$ and e). It has in common with the Tatoosh record northward movement of a field source prior to the reversal, but the motion is not along the longitude bands seen in the intrusion records.

In the model of Leonhardt and Fabian [21], fields on the core mantle boundary and on earth's surface are given throughout the reversal from analysis of four sedimentary records, from well dispersed sites, calibrated for paleointensity with a lava record and tested against the extensive collection of available $\mathrm{B} / \mathrm{M}$ records. This model uses a Bayesian approach to recover spherical harmonics from the four high quality records. It again shows that an important part of the mechanism of the R-N reversal is the transfer of polar flux from south to north. Some northward motion of south polar inward flux is seen early in the reversal sequence (Figure 11c, lower plots), but then low latitude inward radial field develops in the northern hemisphere. It is seen most clearly in the core mantle boundary field although it is evident in the surface fields as well. At $779.5 \mathrm{ka}$ there are inward directed radial flux features in both the northern and southern hemispheres in the surface and core mantle fields, indicating major changes in the non-dipole field close to the polarity switch. The feature in the northern hemisphere continues to move to the north and grow in strength giving the reversal, while the southern hemisphere feature weakens and is replaced by overall outward directed flux in the surface field, although it remains present in the core mantle model field and may possibly is seen as the South Atlantic anomaly in the surface field today. This is an inward flux feature in the predominantly outward flux in the southern hemisphere of the normal polarity field.

Despite the different methods used in the analysis of directional only data [20] and inversion of data including paleointensity
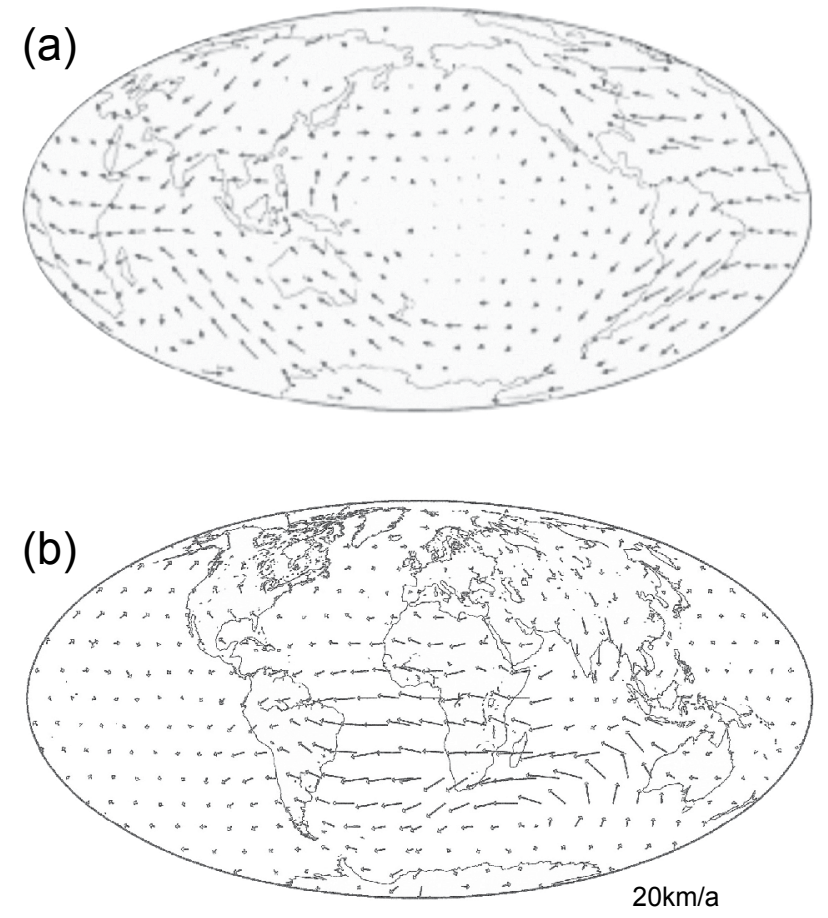

Figure 11: Outer core flow pattern after J. Bloxham and A. Jackson [20]

calibration [21] for the Brunhes-Matuyama, both models show that transfer of a major inward flux feature from south to north plays an important role in R-N reversals. They differ in that near to the midpoint of the latter model the major flux feature divides into two, giving inward flux at intermediate latitudes in both southern and northern hemispheres, whereas in the former the feature remains undivided. Unlike these models, the Upper Olduvai model [19] shows preferred radial flux motion along the longitudes of the Americas and East Pacific. Both the models of Mazaud [19] and Leonhardt and Fabian [21] show more complicated transitional fields than that of Shao et al., [20].

\section{Test of a Possible Role of Outermost Core Flow in the Reversal Process}

Core mantle boundary conditions have long been thought to influence the geomagnetic field and models have been proposed, e.g., Gubbins and Coe [22]. An obvious mechanism is through the outermost core flow. Models of this flow are in general agreement. Figure 11 shows two proposed patterns of flow in the outer core $[23,24]$, which give an impression of the variability of such models. They are also in the two projections used in the following discussion. Given this flow pattern, optimum routes are evident for a major flux feature to follow in either N-R or R-N reversals. Even excursions can be accommodated, for example beginning from a reversed field, after motion along the equatorial flow, the principal flux feature would follow return flow to its original location instead of following the opposite path to give the reversal.

The availability of the field models for reversals provides a test of the role of outer core flow in the reversal process through checking whether the major flux features follow the predicted paths. The field models, which we have, map such features, but may not have sufficient resolution or accuracy to provide a critical test [19-21]. Only the model of Mazaud for the Upper Olduvai N-R reversals gives convincing evidence of motion of radial flux along the longitudes of the Americas and East Asia [19] consistent with the flow pattern prediction. Note however that for the first half of the reversal this motion of inward flux beneath the Americas would be opposite to the 

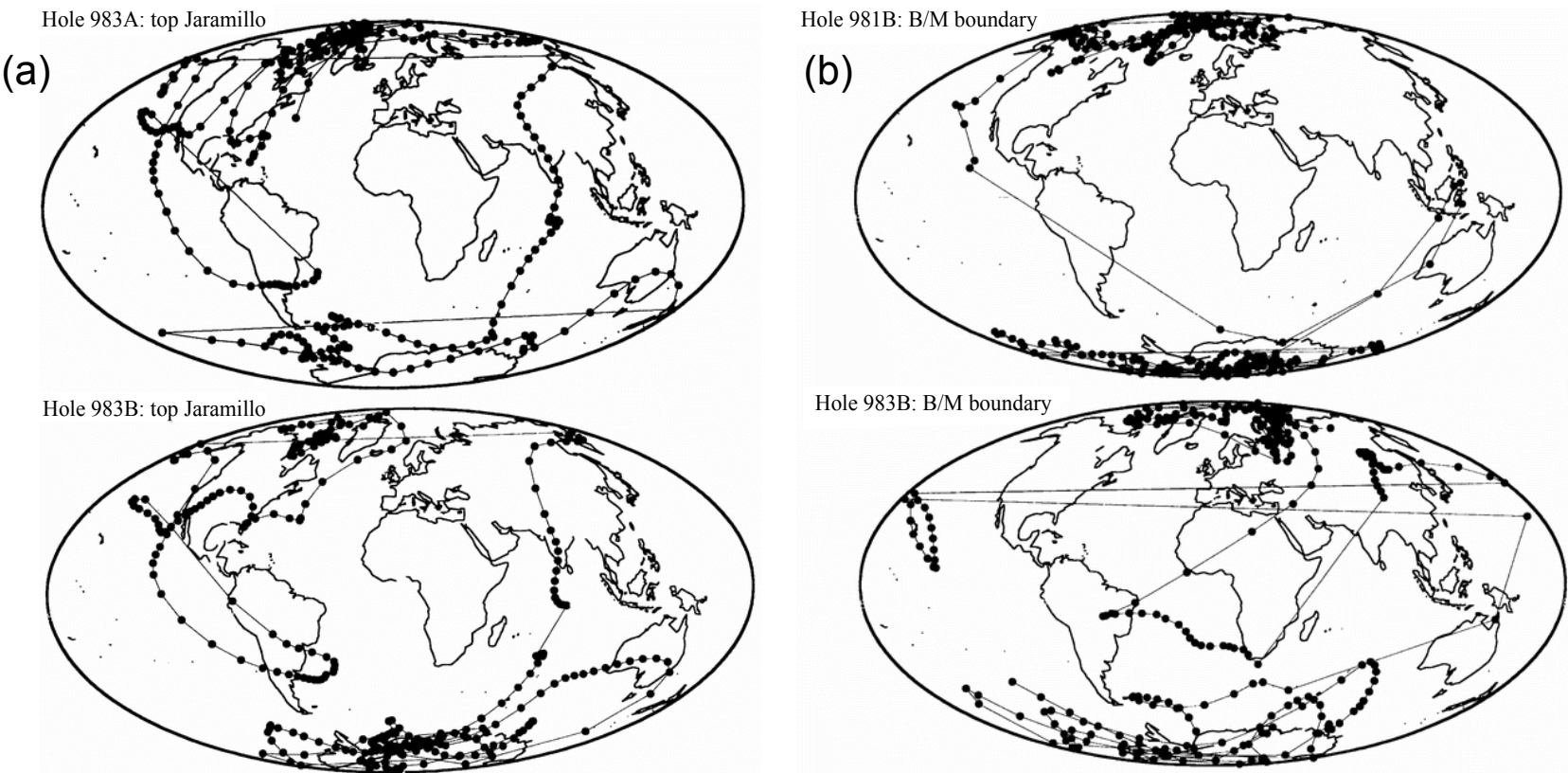

Figure 12: VGP Paths for reversal records from rapidly deposited drift sediments in the North Atlantic [21] (a) Matuyama - Jaramillo and (b) Bruhnes - Matuyama.

sense of the flow in the northern hemisphere and the motion would only coincide with the optimum flow direction in the second half of the reversal (Figure 10a). In the other two models the dominant flux appears to be locked in the longitude of the Atlantic Ocean, with progressive northward motion of this inward directed flux feature. This is not consistent with the flow model. There is some evidence for a role of outer core flow consistent with these field models, but it is equivocal.

\section{Discussion}

The intrusion reversal records confirm aspects of earlier transition studies [1-3], but also add insights, amongst which is the recognition of the significance of the PSV loops in reversals. Occurrences of precursor and rebound PSV loops were found in the intrusion records, as we saw in Sections 3 and 4. The most important insights from those observation are that (1) PSV loops corresponding to the precursor, polarity switch and rebound in the Agno record, give the duration of events within a reversal transition and that of the entire reversal and (2) the growth and northward motion of the PSV loops immediately before the polarity switch in the Tatoosh record (Figure $3 \mathrm{~b}$ plot 4) indicates northward motion of a weakening dipole source at this stage of the transition. The precursors and the rebounds are also seen in the drift sediment records $[25,26]$, and were advocated from analysis of lava records [1].

The observed VGP paths during a reversal reflect the superposition of a shallow sourced non-dipole field and a deeper dipole field, as in the present secular variation. When earth's field is in its stable and non-reversing state the VGP paths are frequently confined to regions of a few degrees at high latitudes. Near the midpoint in the reversal however, the magnitude of the dipole field is much weaker and the non-dipole features may even be stronger than the dipole (Figure 10c). At this stage of the reversal, the VGP appears to track towards the sources giving precursors and rebounds, just as it tracks to the north and south polar regions in the intervals between the precursor, rebound and polarity switch. Following classical descriptions of the non-dipole field, we interpret these sources provisionally as dipoles at the core mantle boundary. The locations of these eccentric dipoles are admittedly not precisely defined, but there are anomalies in the non-dipole field and non-axial dipole fields in the same general areas at present [27].
The PSV loops of precursors and rebounds of N-R and R-N reversals exhibit a remarkable relationship: the precursor and rebound of the N-R reversal become the rebound and precursor of the $\mathrm{R}-\mathrm{N}$ reversal [24]. These precursors and rebounds are most clearly seen in the beautiful drift sediment records of the last reversal and of the N-R reversal at the top of the Jaramillo obtained by Channel and colleagues $[24,25]$. Figure 12 shows two of three virtually identical records of the N-R reversal at the end of the Jaramillo $(\mathrm{M} / \mathrm{J})$. The VGP paths show a precursor phase over the Americas. The path of the polarity switch moves over Asia following strong southward flow to the equator, but continues to the south along similar longitudes against unfavorable flow. The rebound follows paths of favorably directed flow to Australia and back to high latitude reversed poles.

The records of the precursors and rebounds of R-N reversals, shown in figure $12 \mathrm{~b}$, are not as clear as for the N-R reversals. Note that unlike the virtually identical Matuyama-Jaramillo records, these two $\mathrm{B} / \mathrm{M}$ records are very different. The upper record from Hole 981B comes from a section with a lower sedimentation rate than Hole 983B. The differences between the records from slower and faster sedimentation rates are an indication of the difficulties in the interpretation of VGP paths due to smoothing as noted by Channel and Lehman [24]. This is minimized here by concentrating on the VGP paths from the most rapidly deposited drift sediments.

In the record of the $\mathrm{B} / \mathrm{M}$ reversal in Hole 983B, a precursor moves the VGP towards Australia and returns to high latitude southern poles following favorable flow throughout. This is followed by the beginning of a polarity switch, but it appears to be interrupted by a minor loop in the East Pacific. A brief sequence of poles in East Asia follows and then comes a major loop to S. America, which we interpret to be the rebound. Coincidentally with the polarity switch in both N-R and R-N reversals, the dominant non-dipole field features determining the PSV loops before and after the switch also change, so that the precursor and rebound of an N-R reversal do indeed become the rebound and precursor of an R-N reversal.

The precurors and rebounds take the VGP paths to the two principal southern hemisphere VGP clusters in the vicinity of Australia/SE Asia and South America noted by Hoffman [2,27,28]. These are two of the four main non-dipole sources he considers his discussion of the VGPs during transitions, with the other two being in Central America and East Asia, in low northern hemisphere latitudes 
in the same longitudinal bands. Two unexplained observations here are (1) why only two of the four non-dipole features are selected by the VGP paths and transitional clusters and (2) why the VGP paths move to the two selected features independently of the sign of the non-dipole field features, which is positive in Australia/SE Asia and negative in S. America at present.

Given the recognition of the nature and importance of the precursor and the rebound PSV loops discussed above, we return to a possible role of outermost core flow in the reversal process. If we accept that the VGP path tracks major inward flux features of the field, then to be consistent with the observations from the sediments (Figure 12a, b) the following changes in flux distribution are required. The process is clearer in the N-R records (Figure 12a) and so is discussed first. It begins with the initial development of inward flux beneath S. America, which would be opposed to flow from the north geographic pole, but places the VGP at one of the favored cluster sites [2]. This feature disappears during the polarity switch. After the polarity switch a strong inward flux feature takes the VGP path to Australia. The source of this flux is unclear because the field is at minimum during the polarity switch, so that the generation of new inward flux may be required. Finally the flux moves southward to give high southern latitude reverse poles. These movements of the dominant flux features are partially compatible with the outermost core flow pattern.

In an R-N reversal, inward flux must be lost from the southern polar region and gained beneath Australia to give the dominance of the precursor there, which again is a site of VGP clusters [2]. Motion of flux between these two regions would be favorably aligned with outermost core flow. This flux feature disappears during the polarity switch, which is close to the intensity minimum. After the switch there are a few high latitude normal poles and then a strong inward flux patch develops to give the rebound beneath S. America. Again the rebound field appears to require generation of new inward flux. The dipole then continues to gain strength as the inward flux moves to give high northern latitude poles.

In both N-R and R-N reversals motion of the VGP paths towards and away from the precursor and rebound sites could be largely independent of the outermost core flow and simply be the result of the waxing and waning of the relevant field sources. This would be consistent with Hoffmann's discussion [2].

The locations of the precursors and rebounds in the VGP paths are special regions in the outermost core flow. In the vicinity of Australia, north south northern hemisphere flow and south to north flow in the southern hemisphere converge and give east to west flow across the Indian Ocean, Africa, and the South Atlantic to South America. In South America this east to west flow diverges to give north to south in the southern hemisphere and south to north flow in the northern hemisphere. These are likely sites for upwelling and down welling of flux that can generate the features required by the discussion above and postulated by Gubbins and Coe [22].

\section{Conclusion}

We conclude that reversal records from intrusions, such as the Tatoosh, have potential for observing the reversal process and should be studied further, taking advantage of the progress in paleomagnetic techniques in the four decades since the original work described here was done. As seen above, the Agno record shows very clear evidence of three phases in the principal transitional directions at the middle of the reversal record: Phase 1, the precursor, Phase 2 the polarity switch, and Phase 3 the rebound, as suggested by Valet et al., [1]. Phase 1 and 3 are analogous to modern PSV loops lasting 1800 years. The polarity switch may be longer giving a total of $\sim 5400$ years for this part of the reversal in an intensity low of more than $\sim 16,000$ years. As in the Agno record, the major directional changes take place close to the intensity minimum in the Tatoosh record, which is about one order smaller than the field strength prior to and after the reversal. The total time covering the transitional directions in the Tatoosh is difficult to estimate because of the complicated onset and termination of the reversal. However, an estimate of more than some 20,000 years is realistic for the intensity low associated with the reversal and it appears that the principal PSV features at polarity switch appear to last around 5400 years again. These durations are similar to those seen by Channel et al. [24] in the North Atlantic drift sediments. The VGP paths are fixed in mantle coordinates and preferentially follow the longitudes of the Americas and of the West Pacific. In R-N reversals, the south geographic polar flux concentration moves from south to north. The VGP paths during reversals may be explained by the varying contributions of fixed features of the non-dipole field alone in a static field source model [2], or as discussed above may require in addition roles for outermost core flow to bring about flux redistribution [22,29], besides motion of a deeper dipole source consistent with the observation in the Tatoosh [5] and field models of the last reversal $[20,21]$.

These reversal records and field models are still far from providing critical tests to distinguish between dynamo models, such as those developed by Glatzmaier and Coe [30], but successful dynamo models should be consistent with the following observations. (1) The surface field intensity should decrease by an order of magnitude before transitional directions are seen. (2) The intensity low should last at least $\sim 16,000$ years and within this low the central reversal switch and the associated precursor and rebound should take $\sim 5400$ years. (3) The major polar inward flux at the south geographic pole should move northward in R-N reversals, and in a complimentary manner move southward in N-R reversals. (4) VGP paths calculated from the surface fields should give the precursor and rebound transitional PSV loops to South America and to Australia/SE Asia immediately before and after the polarity switch, and while the VGP paths maybe complicated, they should not contain large numbers of latitude parallel circuits of the planet.

\section{Acknowledgments}

We are grateful to Chris Harrison, Ken Hoffman, Jim Channell, and Ji-Cheng Shao, whose comments on earlier versions of this paper were a great help. We thank Bob Dunn and our colleagues, who helped in the original fieldwork and measurements. Thanks also to Nancy Hulbirt and Karen Fuller for help with the diagrams. Special thanks go to Haruaki Ito, whose idea set us out on the original quest for reversal records in intrusions.

\section{References}

1. Valet JP, Fournier A, Courtillot V, Herrero-Bervera E (2012) Dynamical similarity of geomagnetic field reversals. Nature 490: 89-93.

2. Hoffman K (1992) Dipolar reversal states of the geomagnetic field and coremantle dynamics. Nature 359: 789-794.

3. Clement BM (2007) Geomagnetic Polarity Reversals, Observations. In Gubbins D, Herrero-Bervera E (eds) Encyclopedia of Geomagnetism and Paleomagnetism, 324-327.

4. Ratcliff CD, Geissman JW, Perry FV, Crowe BM, Zeitler PK (1994) Paleomagnetic record of a geomagnetic field reversal from late Miocene mafic intrusions, southern nevada. Science 266: 412-416.

5. Dunn JR, Fuller M, Ito H, Schmidt VA (1971) Paleomagnetic Study of a Reversal of the Earth's Magnetic Field. Science 172: 840-845

6. Dodson R, Dunn JR, Fuller M, Williams I, Ito H, et al. (1978) Paleomagnetic record of a late Tertiary field reversal. Geophys, J Roy, Astron Soc 53: 373412.

7. Williams I, Fuller M (1982) A Miocene Polarity Transition (R-N) from the Agno batholith, Luzon. J Geophysical research 87: 9408-9418.

8. Weeks RJ, Dunn JR, Fuller M, Quispesivana L (1990) Analysis of the paleomagnetism and rock magnetism of the Surco intrusion, Peru: an attempt to obtain a southern hemisphere reversal record. Physics of Earth and Planetary Interiors 64: 176-186.

9. Wu, Y-M, Fuller M, Schmidt VA (1974) Microanalysis of N.R.M. in a granodiorite intrusion. Earth and Planetary Science Letters 23: 275-285. 
10. Negrini RM, Erbes DB, Roberts AP, Verosub KL, Sama-Wojcicki AM, et al (1994) Repeating waveform initiated by a 180-190 ka geomagnetic excursion in western North America: Implications for field behavior during polarity transitions and subsequent secular variation. J Geophysical Research 99 24105-24119.

11. Wolfe JA (1972) K-Ar dating in the Philippines. J Geol Soc Philipp 26: 11-12

12. Fuller M, McCabe R, Williams I, Almasco J, Encina RY, et al. (1983) Paleomagnetism of Luzon. In Dennis E. Hayes, The Tectonic and Geologic Evolution of Southeast Asia Seas and Islands: Part 2. Geophysical Monograph Series 27: 79-94.

13. Runcorn SK (1959) On the theory of the geomagnetic secular variation. Ann de Geophys 15: 87-92.

14. Dodson RE (1977) Counterclockwise precession of the geomagnetic field vector and western drift of the non-dipole field. J Geophy Res 84: 637-644

15. Oda H, Shibuya H, Hsu V (2000) Paleomagnetic records of the Brunhes/ Matuyama polarity transition from ODP Leg 124 (Celebes and Sulu Seas). Geophys J Int 142: 319-338.

16. Clement BM, Kent DV (1987) Geomagnetic polarity transition records from five hydraulic piston core sites in the North Atlantic. Initial Rep. Deep Sea Drill 94: 831-852.

17. Laj C, Mazaud A, Weeks R, Fuller M, Herrero-Bervera E (1991) Geomagnetic reversal paths. Nature 351: 447

18. Fuller M (2006) Geomagnetic field intensity, excursions, reversals and the 41,000-yr obliquity signal. Earth Planet Sci Lett 245: 605-615.

19. Mazaud A (1995) An attempt at reconstructing the geomagnetic field at the core-mantle boundary during the Upper Olduvai polarity transition (1.66 Myear). Physics of the Earth and Planetary Interiors 90: 211-219.
20. Shao J-C, Fuller M, Tanimoto T, Dunn JR, Stone DB (1999) Spherical Harmonic analyses of paleomagnetic data: The time averaged geomagnetic field for the past $5 \mathrm{Myr}$ and the Brunhes-Matuyama Reversal. J Geophys Res 104: 5015-5030.

21. Leonhardt R, Fabian $K$ (2007) Paleomagnetic reconstruction of the global geomagnetic field evolution during the Matuyama/Brunhes transition: iterative Bayesian inversion and independent verification. Earth and Planetary Science Letters 253: 172-195.

22. Gubbins D, Coe R (1993) Longitudinally confined geomagnetic reversal from non-dipolar transitional fields. Nature 362: 51-53.

23. Bloxham J, Jackson A (1991) Fluid flow near the surface of the Earth's out core. Rev Geophys 29: 97-120.

24. Maus S, Silva L, Hulot G (2008) Can core surface flow models be used to improve the forecast of the Earth's main magnetic field? J Geophys Res 113.

25. Channell JET, Lehman B (1997) The last two geomagnetic polarity reversals recorded in high-deposition-rate sediment drifts. Nature 389: 712-715.

26. Channell JET, Curtis JH, Flower BP (2004) The Matuyama - Bruhnes boundary interval (500-900 ka) in North Atlantic drift sediments. Geophys J Int 158: 489-505.

27. Constable C (2007) Non-dipole Field. In Gubbins D, Herrero-Bervera E Encyclopedia of Geomagnetism and Paleomagnetism 701-704.

28. Hoffman KA, Singer BA (2004) Regionally Recurrent paleomagnetic Transitional Fields and Mantle Processes. In Channell JET, Kent DV Lowrie W, Meert JG, Timescales of the Paleomagnetic Field. Geophysical Monograph Series, USA 233-243.

29. Gubbins D, Love JJ (1998) Preferred VGP paths during geomagnetic polarity reversals: Symmetry considerations. Geophys Res Lettr 25: 1079-1082.

30. Glatzmaier GA, Coe RS (2007) Magnetic polarity Reversals in the Core. Core dynamics 8: 283-297. 